\title{
Metabolic Control and Serum Hormone Levels in Relation to Retinopathy in Diabetic Pregnancy
}

\author{
J. Larinkari' ${ }^{1}$, L. Laatikainen ${ }^{1}$, T. Ranta ${ }^{2}, 3$, P. Mörönen ${ }^{2}$, K. Pesonen ${ }^{2}$ and T. Laatikainen ${ }^{2}$ \\ 'Department of Ophthalmology and 'Departments I and II of Obstetrics and Gynaecology, University Central Hospital, Helsinki, \\ and ${ }^{3}$ Department of Bacteriology and Immunology, University of Helsinki, Finland
}

\begin{abstract}
Summary. The occurrence and progression of retinopathy were related to the mean blood glucose levels and the serum concentrations of prolactin, human placental lactogen, oestradiol and progesterone in 57 pregnant insulin-dependent diabetic patients. Fifteen patients had frank retinopathy, of whom eight showed a marked increase in retinopathy. The initial blood glucose levels were significantly higher in patients whose retinopathy progressed, whereas during the second and third trimester similar blood glucose levels were achieved in all groups. Serum concentrations of progesterone and human placental lactogen were significantly increased in diabetic patients during the last trimester when compared with those in normal pregnancies, and during the second trimester, patients with retinopathy showed significantly higher concentrations than those without, but no significant difference was found in oestradiol values. The eight patients with progressive retinopathy showed progesterone, human placental lactogen and oestradiol levels at or above the upper limit of the normal range. Throughout gestation, serum prolactin concentrations were significantly lower in diabetic patients than in healthy subjects. No correlation was found between serum prolactin values and the occurrence of retinopathy.
\end{abstract}

Key words: Diabetes mellitus, diabetic pregnancy, diabetic retinopathy, metabolic control, human placental lactogen, progesterone, oestradiol, prolactin.

Progression of diabetic retinopathy has been reported in $3 \%-29 \%$ of diabetic pregnancies $[1,3,10,11]$. The main factors responsible for diabetic retinopathy are thought to be metabolic. During pregnancy, however, an increase in diabetic vasculopathy could also be related to the rapid and marked changes that occur with advancing gestation in the serum patterns of some steroid and protein hormones. In order to establish a possible correlation between progression of retinopathy, metabolic control and the hormonal status in pregnant diabetic patients, a prospective follow-up study comparing mean blood glucose levels and serum concentrations of prolactin, human placental lactogen, oestradiol and progesterone in patients with and without retinopathy, was performed.

\section{Patients and Methods}

Fifty-seven pregnant patients with Type 1 (insulin-dependent) diabetes treated at the I and II Departments of Obstetrics and Gynaecology of the Helsinki University Central Hospital in 1978-1979 were included in the study. In order to achieve good diabetic control, most patients were admitted to the obstetric ward for a short stay during the first trimester, usually between weeks 8 and 12 of pregnancy. All the patients were admitted to hospital during week 24 , and from week 32 until delivery. Between these admissions, the patients were seen on an out-patient basis every second week and further admitted when needed.

Ophthalmological examination, including direct and indirect ophthalmoscopy and colour photography of the fundus, was performed by one of the authors at the end of the first and second trimester, just before or after delivery, and 3-6 months after delivery. The photographs were evaluated by another author who was unaware of the ophthalmoscopic findings, or of any other data concerning the patients. On the basis of the initial ophthalmoscopy, the patients were divided into two groups: (1) no or minimal retinopathy with less than ten microaneurysms per eye (group A), and (2) frank retinopathy including both background and proliferative retinopathy. The latter group was later divided into non-progressive (group B) and progressive (group C) retinopathy. The criteria of the progression were a considerable increase in the number of microaneurysms and haemorrhages or the development of fresh cotton wool spots or neovascularisation, observed both by ophthalmoscopy and in colour photographs.

Blood glucose levels were determined during each hospital stay by one or several $24 \mathrm{~h}$ profiles with samples taken at $4 \mathrm{~h}$ intervals. 
Table 1. Characteristics of the patients studied

\begin{tabular}{llllll}
\hline Group & $\begin{array}{l}\text { Retino- } \\
\text { pathy }\end{array}$ & $\begin{array}{l}\text { Number } \\
\text { of } \\
\text { patients }\end{array}$ & $\begin{array}{l}\text { Age of } \\
\text { patients } \\
\text { (years) }\end{array}$ & $\begin{array}{l}\text { Age at } \\
\text { onset of } \\
\text { diabetes } \\
\text { (years) }\end{array}$ & $\begin{array}{l}\text { Duration } \\
\text { of } \\
\text { diabetes } \\
\text { (years) }\end{array}$ \\
\hline A & $\begin{array}{l}\text { Nil or } \\
\text { minimal }\end{array}$ & 42 & $27(20-38)$ & $16(2-33)$ & $9(1-28)$ \\
B & $\begin{array}{l}\text { Non-pro- } \\
\text { gressive }\end{array}$ & 7 & $28(23-34)$ & $16(10-22)$ & $13(10-19)$ \\
C & $\begin{array}{l}\text { Pro- } \\
\text { gressive }\end{array}$ & 8 & $26(22-40)$ & $11(2-22)$ & $18(9-28)$ \\
\hline
\end{tabular}

Results expressed as median (range)

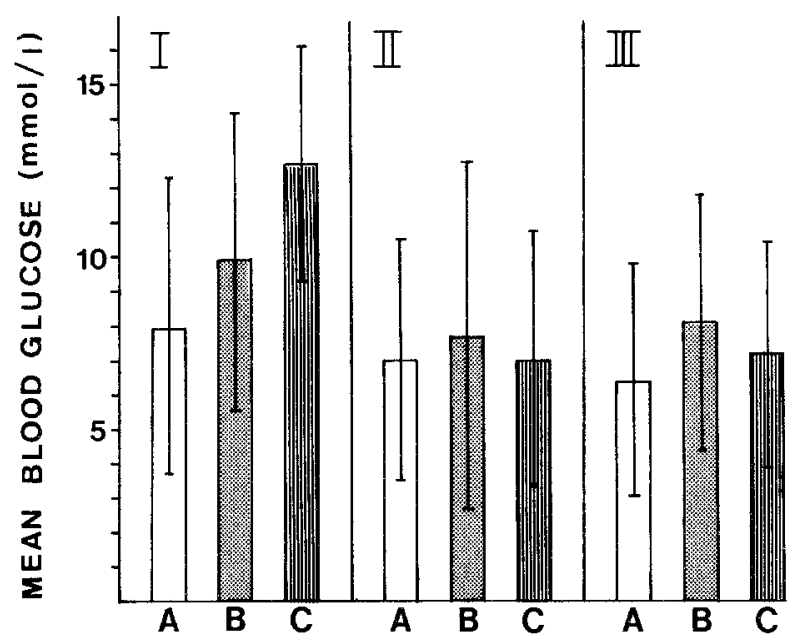

Fig. 1. Mean blood glucose concentration ( \pm SD) of $24 \mathrm{~h}$ glucose profiles in patients without frank retinopathy $(\mathrm{A})$, with non-progressive (B) and progressive (C) retinopathy during the first trimester (I), and during the second (II) and third trimester (III) of pregnancy

The mean glucose level of each profile was calculated. During the first trimester, the daily follow-up after the first admission to hospital was used to represent the basic diabetic control of each patient. After that, the daily insulin was adjusted to two to four doses in order to keep the patients' blood glucose level near to normal. During the second and third trimester, two sets of $24 \mathrm{~h}$ profiles were used for the calculation of the mean blood glucose level in each patient. Blood glucose was measured with the glucose oxidase method.

Blood samples for hormone determinations were collected approximately every 6 weeks. Altogether 224 blood samples from the diabetic patients were studied. In order to establish the normal limits of hormone levels with advancing gestation, blood samples were collected from 58 healthy pregnant women admitted to the hospital for interruption of pregnancy because of social reasons, at 6 to 12 weeks of gestation. Serial blood samples were collected from 24 additional healthy women in weeks $13-38$ of pregnancy at a maternal outpatient clinic.

Serum concentrations of oestradiol and progesterone were measured by radioimmunoassay. The specificity of the antisera used for the assays of progesterone [12] and oestradiol [13] has been described earlier. The dextran coated charcoal method was used for the separation of bound and unbound radioactivity. The mean intra-assay coefficients of variation in the determinations of oestra- diol and progesterone were 7.8 and $8.9 \%$, respectively. Serum prolactin concentrations were measured by a homologous radioimmunoassay as described previously [16]. A prolactin standard (NPA Batch hPRL No.5) from the National Pituitary Agency, Bethesda, Maryland, was used. Human placental lactogen was measured using a commercial radioimmunoassay (Pharmacia, Uppsala, Sweden)

The $95 \%$ tolerance limits for the hormone values in the healthy group were estimated according to Herrera [8]. Student's t-test was employed in the statistical comparisons.

\section{Results}

\section{Retinopathy}

Forty-two patients (group A, Table 1), initially had no or minimal retinal changes. In the course of pregnancy, no significant increase in retinopathy was observed in these patients.

Fifteen patients (groups B and C, Table 1) had frank retinopathy. Three had proliferative changes and 12 had background retinopathy. In eight (group C) of the 15 patients, a considerable increase in retinopathy was observed particularly during the second trimester of pregnancy, with the appearance of multiple cotton wool spots and other intra-retinal microvascular abnormalities in seven patients and neovascularisation of the optic disc in one. This patient was treated with panretinal argon laser photocoagulation during her pregnancy, and no further progression of retinopathy was observed during the 2 year postpartum follow-up. After delivery, fresh cotton wool spots were seen in only two of the eight patients and some increase in the background retinopathy was seen in another two. In the other cases, cotton wool spots resolved, and venous congestion and retinal oedema decreased just before or soon after delivery. The central visual acuity was transiently impaired in two patients because of macular oedema, but neither of them became blind.

Elevated blood pressure $(>140 / 90 \mathrm{mmHg}$ ) was initially found in two patients, one in group B, the other in group C. The latter developed severe pre-eclampsia. In addition, three patients with non-progressive retinopathy and one without retinopathy had slightly elevated blood pressure $(<160 / 110 \mathrm{mmHg})$ just before delivery. Three of these patients had proteinuria.

\section{Diabetic Control}

The mean blood glucose levels of the $24 \mathrm{~h}$ glucose profiles in groups $\mathrm{A}-\mathrm{C}$ with advancing gestation are seen in Figure 1. In the fïrst glucose profile during the first trimester, the mean ( \pm SD) blood glucose values 

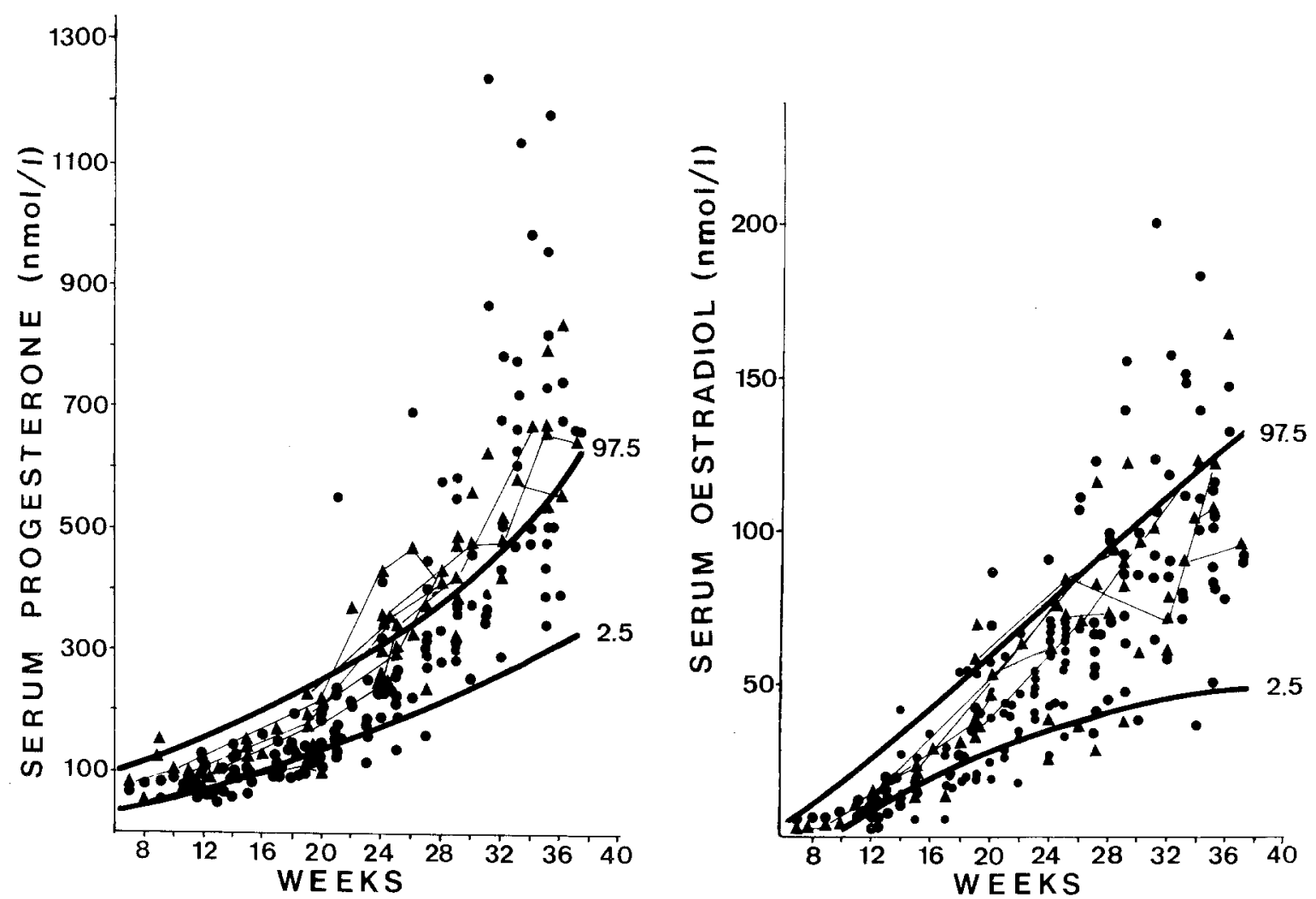

Fig. 2. Distribution of serum progesterone and oestradiol values in diabetic pregnancies in relation to the $95 \%$ tolerance limits of the control group. patients without retinopathy, $\Delta$ patients with retinopathy. Values of patients with progressive retinopathy are connected

were significantly higher in patients with non-progressive $(9.9 \pm 4.3 \mathrm{mmol} / 1, p<0.05)$ and progressive retinopathy $(12.7 \pm 3.3 \mathrm{mmol} / 1, p<0.001)$ than in those without retinopathy $(7.9 \pm 4.2 \mathrm{mmol} / 1)$, but after adjustment of diet and insulin dosage similar blood glucose levels were achieved in all three groups. Eight of the 42 patients in group $A$ and 10 of the 15 patients in groups $\mathrm{B}$ and $\mathrm{C}$ received three to four doses of insulin daily and the remainder two doses.

\section{Oestradiol and Progesterone}

Serum concentrations of oestradiol and progesterone with advancing gestation are depicted in Figure 2. In a few diabetic patients, elevated oestradiol values were observed during the last trimester, but the values at the 6 weekly assessments did not differ significantly from those in the healthy subjects. In addition, oestradiol values in the diabetic patients with frank retinopathy did not differ from those in the patients with no or minimal retinal changes. In the patients with progressive retinopathy, most values of oestradiol after week 19 were at the upper limit of normal.

During the second and last trimester of pregnancy, progesterone values were elevated in several diabetic patients. At weeks 32-37 of pregnancy, the mean
Table 2. Comparison of progesterone levels in pregnant diabetic patients without and with frank retinopathy

\begin{tabular}{|c|c|c|c|}
\hline \multirow{2}{*}{$\begin{array}{l}\text { Pregnancy } \\
\text { week }\end{array}$} & \multicolumn{2}{|c|}{ Serum progesterone $(\mathrm{mmol} / \mathrm{l})$} & \multirow[b]{2}{*}{$p$} \\
\hline & $\begin{array}{l}\text { Diabetes without } \\
\text { retinopathy }\end{array}$ & $\begin{array}{l}\text { Diabetes with } \\
\text { retinopathy }\end{array}$ & \\
\hline $7-13$ & $73 \pm 3.2(24)$ & $93 \pm 8.2(11)$ & NS \\
\hline $14-19$ & $117 \pm 4.8$ & $162 \pm 11$ & $<0.001$ \\
\hline $20-25$ & $205 \pm 13$ & $277 \pm 26$ & $<0.02$ \\
\hline $26-31$ & $379 \pm 39$ & $424 \pm 25$ & NS \\
\hline $32-37$ & $658 \pm 39$ & $611 \pm 47$ & NS \\
\hline
\end{tabular}

Results expressed as mean \pm SEM. Number of determinations in parentheses

level of progesterone in diabetic pregnancies was $644 \mathrm{nmol} / 1$, which is significantly higher than the mean value of $470 \mathrm{nmol} / 1$ in the control group $(p<$ 0.001 ). In Table 2 , the mean progesterone concentrations in the diabetic pregnancies with and without frank retinopathy are compared. In the former group, significantly higher progesterone values were found at weeks $14-25$. After week 20 , all patients with progressive retinopathy had progesterone levels above the normal range (Fig. 2). 

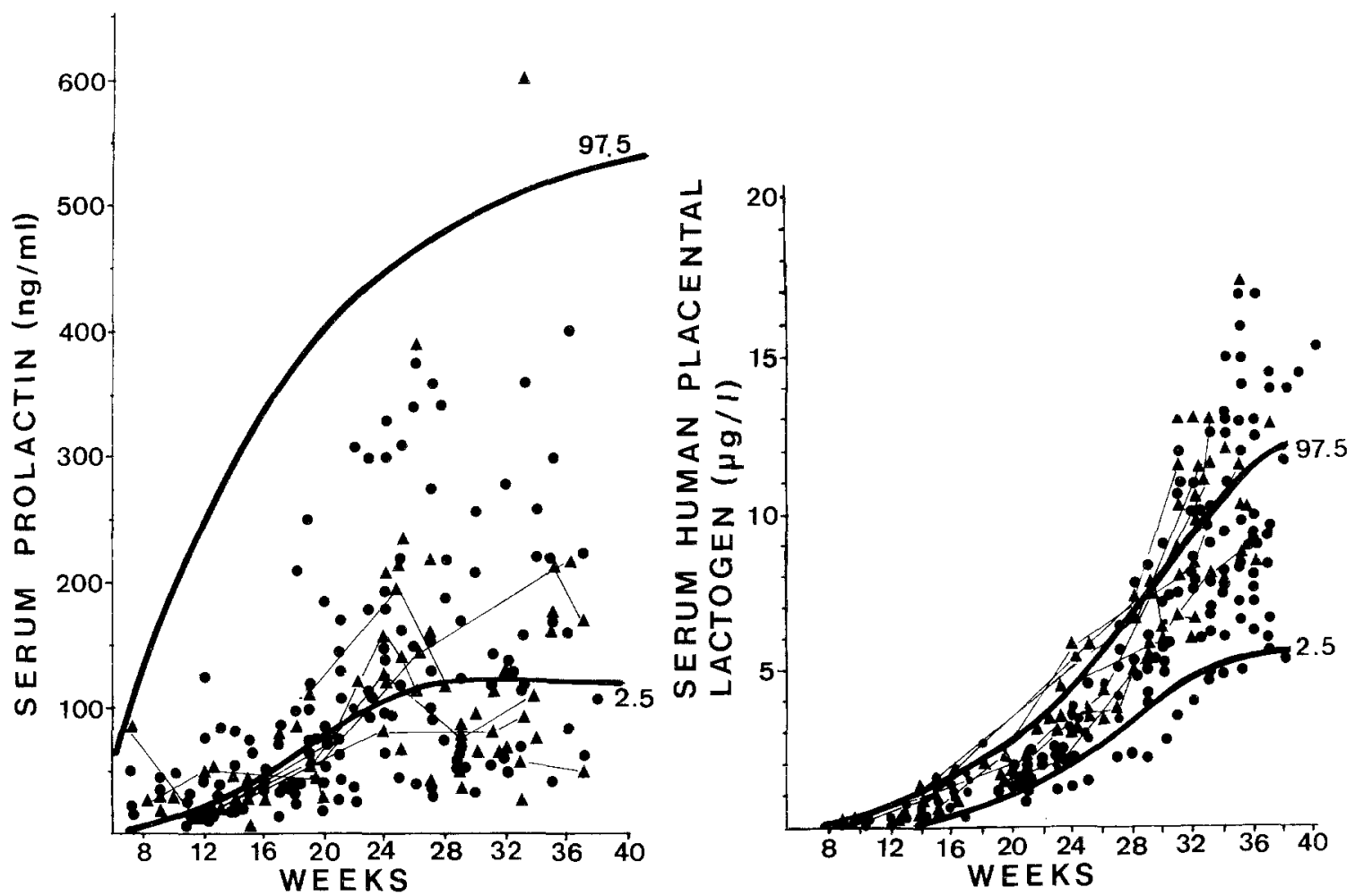

Fig.3. Distribution of serum prolactin and human placental lactogen values in diabetic pregnancies in relation to the $95 \%$ tolerance limits of the control group. patients without retinopathy, $\Delta$ patients with retinopathy. Values of patients with progressive retinopathy are connected

Table 3. Comparison of human placental lactogen levels in pregnant diabetic patients without and with frank retinopathy

\begin{tabular}{|c|c|c|c|c|}
\hline $\begin{array}{l}\text { Pregnancy } \\
\text { week }\end{array}$ & $\begin{array}{l}\text { Diabetes without } \\
\text { retinopathy }\end{array}$ & $\begin{array}{l}\text { Diabetes with } \\
\text { retinopathy }\end{array}$ & & $p$ \\
\hline $8-13$ & $0.22 \pm 0.07 \quad(8)$ & $0.27 \pm 0.16$ & (4) & NS \\
\hline $14-19$ & $0.82 \pm 0.089$ & $1.58 \pm 0.16$ & (12) & $<0.01$ \\
\hline $20-25$ & $2.52 \pm 0.17$ & $3.76 \pm 0.31$ & (14) & $<0.01$ \\
\hline $26-31$ & $6.24 \pm 0.43$ & $7.66 \pm 0.53$ & (19) & NS \\
\hline $32-37$ & $9.7 \pm 0.43$ & $10.5 \pm 0.30$ & (22) & NS \\
\hline
\end{tabular}

Results expressed as mean \pm SEM. Number of determinations in parentheses

\section{Prolactin and Human Placental Lactogen}

Serum levels of prolactin and human placental lactogen in diabetic pregnancies are depicted in Figure 3. After week 28 of gestation, the human placental lactogen values of several diabetic patients were high in comparison with those of the healthy subjects. At weeks 34-36 of gestation, the mean human placental lactogen value in the diabetic patients $(10.4 \mu \mathrm{g} / \mathrm{ml})$ was significantly higher than that in the healthy subjects $(7.18 \mu \mathrm{g} / \mathrm{ml}, p<0.001)$. Human placental lactogen levels in the patients with and without frank ret- inopathy are compared in Table 3 . In the former group, the mean human placental lactogen values were significantly higher at weeks $14-25$ of gestation. The patients with progressive retinopathy are depicted in Figure 3. After week 28 the human placental lactogen values of these patients were at or above the upper limit of normal.

Prolactin values showed considerable variation among both normal and diabetic subjects. In the diabetic patients, prolactin values were lower than those in the healthy pregnant patients, e.g. at weeks 10-14 the mean prolactin level in diabetic subjects was $33.3 \mathrm{ng} / \mathrm{ml}$ and in the normal subjects $142 \mathrm{ng} / \mathrm{ml}(p<$ 0.001 ), and at weeks $23-27$ the corresponding values were 166 and $300 \mathrm{ng} / \mathrm{ml}$ respectively $(p<0.001)$. The mean values of prolactin revealed no difference between the patients with and without frank retinopathy, nor did prolactin levels in the patients with progressive retinopathy differ from those in the other patients.

\section{Discussion}

If the patients with minimal retinal changes are excluded, $27 \%$ of the diabetic patients in this study had retinopathy, which falls within the $13-40 \%$ preval- 
ence reported earlier [1,3,10,11]. Progression of retinopathy was found in $14 \%$ of our patients. Many factors have been suggested to influence the development and progression of diabetic vascular disease, the most important of them being duration of diabetes, high blood glucose levels and elevated blood pressure [19]. All our pregnant patients with retinopathy had suffered from diabetes for at least 9 years. There was no difference in the age distribution of the patients in the various groups. The median duration of diabetes was, however, longer in patients with retinopathy and longest in those whose retinopathy progressed. These patients also showed the highest blood glucose values when first admitted to the hospital, but after adjusting the diet and insulin dose this group did not differ from the remainder. Thus, although relatively good metabolic control was achieved in most of the patients during the second and third trimesters of pregnancy, deterioration in the retinal changes, especially progression of capillary occlusion, could not be prevented. Attention should therefore be paid to diabetic control from the beginning of pregnancy. The importance of good metabolic control during the first trimester of pregnancy has also been emphasized in an attempt to reduce the risk of congenital malformations [5].

In the present study, the serum levels of progesterone and human placental lactogen were significantly higher in the diabetic than in the healthy subjects in the last trimester of pregnancy. These hormones are produced by the placenta, and progesterone concentration has been shown to correlate with the weight of the placenta [17]. In diabetic patients, elevated values of human placental lactogen [15] and progesterone may be related to the greater placental weights known to be associated with these pregnancies [2]. In 12 of our patients, in whom serum progesterone values at weeks 32-36 of gestation (Fig. 2) were high (> $700 \mathrm{nmol} / \mathrm{l})$, the mean placental weight, including the cord and membranes, was $900 \mathrm{~g}$ compared with about $600 \mathrm{~g}$ in an uncomplicated pregnancy. Elevated serum oestradiol concentration in diabetic pregnancies during the last trimester has been reported [4], but in the present study the mean serum oestradiol level in the diabetic patients did not differ significantly from that in the healthy subjects, although some elevated values were found during the last trimester.

Comparison of progesterone and human placental lactogen levels in patients with and without retinopathy, showed that during the second trimester, concentrations of both hormones were significantly higher in patients with retinopathy than in those without. Further studies are needed to clarify whether this is due to an impaired elimination of these hormones as a result of diabetic vasculopathy in the liver and kidney. In the patients with progressive retinopathy the values of progesterone, human placental lactogen and oestradiol were all elevated or at the upper limit of normal, and most of the cotton wool spots appeared during the second trimester, when both progesterone and human placental lactogen levels were significantly increased when compared with those in patients without retinopathy. High hormone levels and progression of retinopathy may both be due to the poor metabolic control found in these patients during the first trimester of pregnancy, but it is also possible that placental hormones are one of the factors contributing to capillary occlusion and micro-infarcts observed in the retina in many of the patients with preceding retinopathy.

In the course of normal pregnancy, the serum concentration of prolactin rises progressively [18]. Larger studies on serum prolactin in diabetic pregnancy are lacking although low concentrations have occasionally been reported [14]. In the present series, prolactin values were significantly lower in the diabetic patients than in the healthy subjects throughout the pregnan$c y$. The cause and significance of this finding remains unexplained. Earlier studies on serum prolactin level in relation to retinopathy in non-pregnant diabetic patients have been controversial $[6,7,9]$. In this study, no difference was found in prolactin levels between the patients with and without retinopathy, suggesting that serum prolactin level and diabetic retinopathy are not correlated.

Acknowledgements. This study was supported financially by the Finnish Cultural Foundation.

\section{References}

1. Beetham WP (1950) Diabetic retinopathy in pregnancy. Trans Am Ophthalmol Soc 48: 205-216

2. Benirschke K, Driscoll SG (1967) In: Strauss F, Benirschke K, Driscoll SG (eds) Placenta. Springer, Berlin Heidelberg New York, p 553

3. Cassar J, Kohner EM, Hamilton AM, Gordon H, Joplin GF (1978) Diabetic retinopathy and pregnancy. Diabetologia 15: 105-111

4. De Hertog R, Thomas K, Hoet JJ, Vanderheyden I (1976) Plasma concentrations of unconjugated oestrone, oestradiol-17 $\beta$ and oestradiol, and HCS throughout pregnancy in diabetics and gestational diabetics. Diabetologia 12:455-461

5. Freinkel N (1980) Of pregnancy and progeny. Diabetes 29 : 1023-1035

6. Frøland A, Hagen C, Lauritzen E (1977) Diabetic retinopathy and prolactin. Lancet 1: 45

7. Harter M, Balarac N, Pourcher Ph, Koslowski JM, Krebs B, Ramaioli A (1976) Diabetic retinopathy and prolactin. Lancet 2: $961-962$

8 . Herrera $L$ (1958) The precision of percentiles in establishing normal limits in medicine. J Lab Clin Med 52:34.42

9. Hunter PR, Anderson J, Lunn TA, Horrobin DF, Boyns AR, Cole EN (1974) Diabetic retinopathy and prolactin. Lancet 1 : 1237 
10. Janert H, Mohnike G, Georgi P (1957) Ophthalmologische Diabetesstudien III. Retinopathia proliferans und Iridopathie. Klin Wochenschr 35: 110-119

11. Jervell J, Moe N, Skjaeraasen J, Blystad W, Egge K (1979) Diabetes mellitus and pregnancy. Management and results at Rikshospitalet, Oslo 1970-1977. Diabetologia 16: 151-155

12. Jänne O, Apter D, Vihko R (1974) Assay of testosterone, progesterone and $17 \alpha$-hydroxyprogesterone in human plasma by radioimmunoassay after separation on hydroxyalkoxypropyl Sephadex. J Steroid Biochem 5: 155-162

13. Lindberg BS, Lindberg P, Martinsson K, Johansson EDB (1974) Oestrogens during pregnancy I. Radioimmunological methods for the estimation of oestrone, oestradiol-17 $\beta$, and oestriol in pregnancy plasma. Acta Obstet Gynecol Scand (Suppl) 32:5-19

14. Sadovsky E, Weinstein D, Ben-David M, Polishuk WZ (1977) Serum prolactin in normal and pathologic pregnancy. Obstet Gynecol 50:559-561

15. Selenkow HA, Varma K, Younger D, White P, Emerson K (1971) Patterns of serum immunoreactive human placental lactogen (IR-HPL) and chorionic gonadotropin (IR-HCG) in diabetic pregnancy. Diabetes 20:696-706
16. Seppälä M, Hirvonen E, Ranta T, Virkkunen P, Leppäluoto J (1975) Raised serum prolactin levels in amenorrhoea. Br Med J 2:305-306

17. Spellacy WN, Conly PW, Cleveland WW, Buhi WL (1975) Effects of fetal sex and weight and placental weight on maternal serum progesterone and chorionic gonadotropin concentrations. Am J Obstet Gynecol 122: 278-282

18. Tyson JE, Hwang P, Guyda H, Friesen HG (1972) Studies on prolactin secretion in human pregnancy. Am J Obstet Gynecol 113:14-20

19. Williamson JR, Kilo C (1980) Vascular complications in diabetes mellitus. N Engl J Med 302: 399-400

Received: 23 July 1981

and in revised form: 15 December 1981

Timo Laatikainen, M.D.

Departments of Obstetrics and Gynaecology

University Central Hospital

Haartmaninkatu 2

SF-00290 Helsinki 29, Finland 